\title{
Development and evaluation of male-only strains of the Australian sheep blowfly, Lucilia cuprina
}

\author{
Maxwell J Scott
}

\begin{abstract}
The Australian sheep blowfly Lucilia cuprina (Wiedemann) is a major pest of sheep in Australia and New Zealand. From the 1960s to the 1980s there was a major effort to develop "field female killing" or FFK strains of L. cuprina that could be used for a cost-effective genetic control program. The FFK strains carried eye color mutations that were lethal to females in the field but not under conditions in the mass rearing facility. Males did not die in the field as normal copies of the eye color genes had been translocated to the $\mathrm{Y}$ chromosome and an autosome. Although the FFK strains showed some promise in field tests, a genetic control program in mainland Australia was never implemented for several reasons including instability of the FFK strains during mass rearing. A stable transgenic strain of L. cuprina that carried one or more dominant repressible female lethal genes offered the potential for efficient genetic control of blowfly populations. Here I review our research on tetracycline-repressible female lethal genetic systems, Lucilia germ-line transformation and sex determination genes that ultimately led to the successful development of transgenic "male-only" strains of L. cuprina. The technology developed for L. cuprina should be directly transferable to other blowfly livestock pests including L. sericata and the New World and Old World screwworm. 29
\end{abstract}

\section{Background}

Female Lucilia cuprina lay eggs on the live animal and their larval offspring cause a cutaneous myiasis (flystrike) in sheep. L. cuprina is the major primary strike fly (fly that causes flystrike) in Australia [1] and an increasingly significant strike fly in New Zealand [2]. Flystrike can lead to reduced wool quality and quantity and death of the animal if not treated, which largely involves the widespread use of insecticides and good farming practices. The annual economic cost of flystrike is estimated to be AUS \$280 million in Australia [3] and NZ \$30-40 million in New Zealand [2]. For many years there was considerable interest in developing strains of L. cuprina that could be used for efficient genetic control programs. These efforts were inspired by the success of the sterile insect technique (SIT) in eradicating the related New World screwworm fly (Cochliomyia hominivorax) from the U.S.A. $[4,5]$. Subsequently, New World screwworm was eradicated from all North and Central America [5]. SIT involved mass rearing of the insect, sterilization by radiation and aerial release of sterile males and females

Correspondence: mjscott3@ncsu.edu

Department of Entomology, North Carolina State University, Campus Box 7613, Raleigh, NC, 27695-7613, USA over the targeted area. As the sterile males were in a large excess (at least 9:1) over fertile males in the field, the fertile females in the area were more likely to mate with the sterile males. For genetic control of L. cuprina to be cost-effective in Australia, strains were developed that were predicted to be more effective at lower release ratios than a bisexual release and that did not need to be sterilized by radiation $[6,7]$. The latter would eliminate the need for a central large expensive mass rearing facility built around a radiation device. Instead several smaller facilities could be built which were expected to be more cost effective given the size of the Australian continent and distribution of sheep blowfly [7]. Eliminating the radiation step could also improve the fitness of the released males, as radiation does reduce the fitness of C. hominivorax males [8].

"Field female killing (FFK)" strains were developed that were homozygous for two autosomal recessive eye color mutations that essentially made the females blind in the field [7]. The FFK strains carried multiple chromosomal translocations involving the $\mathrm{Y}$ chromosome and the two autosomes that had normal copies of the eye color genes. Consequently, males were not blind and were semi-sterile, as most of their offspring would 
not develop due to aneuploidy. The combination of male semi-sterility and recessive female lethality was predicted to make the FFK strain more effective at population reduction than SIT, particularly at the more cost-effective low release ratios [9]. Indeed, a small island $\left(40 \mathrm{~km}^{2}\right)$ trial in 1985-1986 was successful, achieving a very high genetic death and suppressing the L. cuprina population to undetectable levels [7]. A subsequent larger island field trial initially had some success but ultimately failed. There were problems with mass rearing the strain, which was unstable and prone to breakdown due to recombination in males. With a decline in the wool price, the L. cuprina genetic control program was abandoned. Nevertheless, the concept of releasing flies that were not sterilized by radiation but carried female lethal genes had been established [10].

\section{Development and evaluation of tetracycline-repressible} female lethal genetic systems in Drosophila melanogaster The successful germ-line transformation of D. melanogaster in 1982 [11] opened the potential for making transgenic insect strains carrying female lethal genetic systems. As females would be needed for mass rearing, female-specific lethality needed to be repressible. In the mid 1990s, not long after establishing our laboratory at Massey University in New Zealand, we began building and testing such genetic systems in D. melanogaster since there were many genetic tools available for Drosophila engineering. Also a method for germ-line transformation of L. cuprina and not yet been developed.

To achieve female-specific gene expression, it was apparent that this required either a gene promoter that was female-specific or an intron that was sex-specifically spliced. For the latter, we turned to the genes that are part of the well-characterized Drosophila sex determination regulatory pathway [12]. Transcripts from the master gene Sex lethal, from the transformer (tra) gene and from the doublesex $(d s x)$ gene were all known at that time to be sex-specifically spliced. Wilkins had suggested that the genes at the bottom of the regulatory pathway, $d s x$ and fruitless, would be more highly conserved than the master gene at the top of the pathway [13]. This hypothesis has largely proven to be correct. Consequently, we focused on using the sex-specifically spliced intron from the $D$. melanogaster $d s x$ ( $D m d s x$ ) gene as we reasoned that $d s x$ transcripts were also likely to be sexspecifically spliced in L. cuprina. Steller and colleagues had shown that widespread expression of the proapoptotic gene head involution defective (hid), also known as Wrinkled $(W)$, led to organismal death [14]. Thus we decided to insert the Dmdsx intron within the hid gene to obtain a female-specific lethal gene. Expression was controlled with the heat inducible $h s p 70$ gene promoter [15] (Figure 1). The expectation was that after a heat
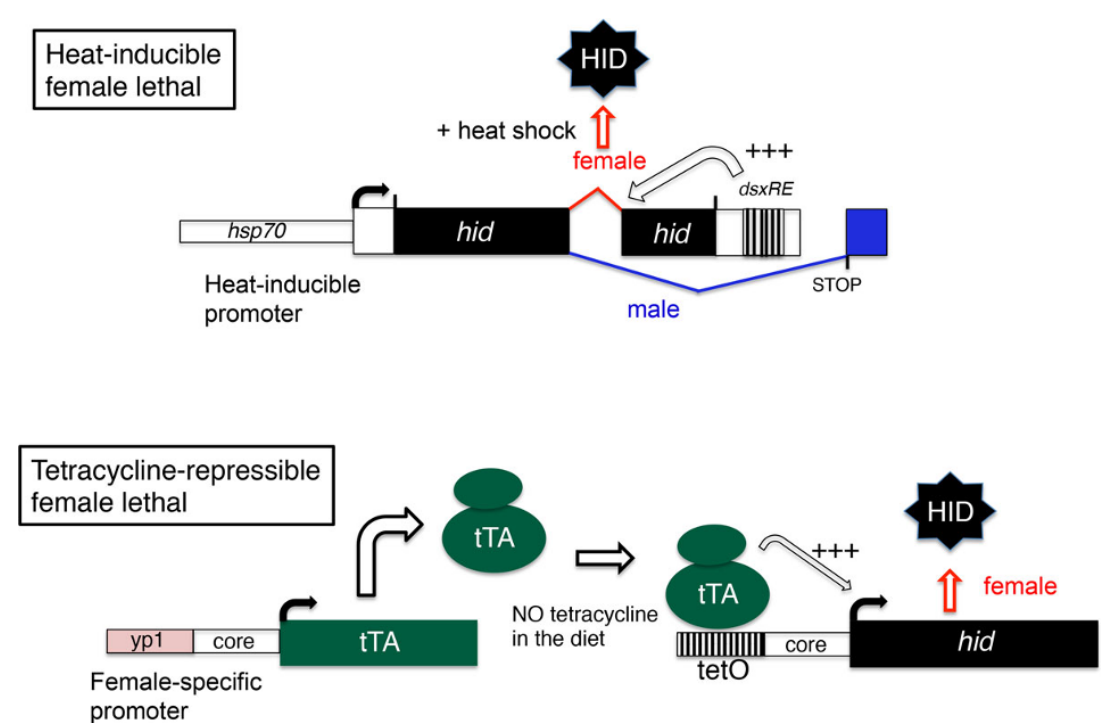

Figure 1 Conditional female lethal genetic systems evaluated in Drosophila melanogaster. (Top) Heat inducible female lethal system. The hid open reading frame was interrupted with the female-specific intron from the $d s x$ gene, which contains a weak splice acceptor site. Immediately $3^{\prime}$ of hid was the $d s x R E$, which includes several TRA/TRA2 binding sites. Binding of TRA/TRA2 to the dsxRE enhances (+++) splicing of the $d s x$ intron in females. Further downstream was the intron-exon from the Dror2 gene, which has an optimal splice acceptor site. Males were predicted to use the stronger Dror2 splice site whereas females would use the $d s x$ acceptor site. Thus only the female hid transcript was predicted to encode full-length protein. (Bottom) Tetracycline-repressible female lethal system. On normal diet, expression of tTA in the female fat body of third instar larvae led to activation $(+++)$ of hid gene expression and female-specific lethality. Lethality was repressed by the addition of tetracycline to the diet. 
shock, $D$. melanogaster females would die, as only the female hid transcript would code for fully functional HID protein. Unfortunately, after heat shock both males and females died as in both sexes hid transcripts were spliced using the weak female-specific $D m d s x$ splice acceptor site. It appeared that the hid transcript contained a nucleotide sequence that enhanced the use of the weak female acceptor site in both sexes [15].

Fortunately, the alternative approach of using a female-specific gene promoter was more successful. A $125 \mathrm{bp}$ enhancer from the yolk protein 1 (yp1) gene had been shown to drive expression of a reporter gene in female fat body [16]. This could have been used to control expression of hid to achieve female lethality but this system would not have been conditional. To achieve regulated expression of hid, we placed the tetracyclinedependent transactivator or tTA gene under the control of the $y p 1$ enhancer (Figure 1). tTA is a fusion of the DNA binding domain from the Escherichia coli tet repressor (tetR) and the viral VP16 transcription activation domain [17]. In the presence of tetracycline, tTA does not bind to the operator $(t e t O)$ from the $E$. coli tetracycline-resistance operon [17]. We found that in transgenic Drosophila, yp1-tTA activated expression of a tetO-lac $Z$ reporter gene in female fat bodies but only in the absence of tetracycline [18]. Thus we had a made a female-specific conditional expression system. The last step was to make tetO-hid "effector" lines and cross with yp1-tTA "drivers" (Figure 1). We found that females carrying both components died unless tetracycline was added to the diet [18]. Thus we had developed a transgenic FFK system. Unknown to us, a group in Oxford led by Luke Alphey had developed an almost identical system, which they called RIDL for "release of insect carrying dominant lethals" [19]. Modeling suggested that the RIDL system would be more efficient than SIT [19], particularly if the strains carried multiple repressible female-lethal genes that had low fitness costs [20]. It should be noted that, although there are several studies on fitness costs in transgenic RIDL strains (e.g. $[21,22]$ and references therein), this remains to be evaluated under mass rearing and under field conditions.

\section{Germ-line transformation of L. cuprina}

Drosophila transformation was achieved by using vectors based on the $P$ transposable element. However, plasmidbased mobility assays showed that the $P$ element was not functional outside of Drosophilidae [23]. Thus the first step in developing a L. cuprina transformation system was to identify transposable elements that were functional in L. cuprina embryos. Peter Atkinson and colleagues used interplasmid transposition assays to show that the mariner transposable element was functional in L. cuprina [24]. We used similar assays to show that the
Minos and piggyBac transposable elements were active in L. cuprina embryos [25]. The next step was to identify a marker gene that could be used to identify transgenic L. cuprina. Initially we used eye color genes as several L. cuprina strains carrying eye color mutations were available, including white eye. However, our attempts at making transgenic L. cuprina using Minos or piggyBac vectors carrying the medfly white gene as a marker were unsuccessful [25]. An alternative to eye color genes were fluorescent protein marker genes [26]. An EGFP gene driven by the $D$. melanogaster polyubiquitin promoter (PUbnlsEGFP) had been successfully used to identify transgenic D. melanogaster and Anastrepha suspensa $[27,28]$. Using a piggyBac vector containing this EGFP marker gene we were successful in transforming L. cuprina [25]. The same vector was subsequently used to make transgenic C. hominivorax [29].

Although we had succeeded in making transgenic L. cuprina, the overall efficiency was low and most experiments did not produce any transgenic flies. One reason for the low efficiency appeared to be because the D. melanogaster polyubiquitin promoter was weakly active in L. cuprina (and C. hominivorax), which made it difficult to distinguish transgenic from non-transgenic larvae. Consequently, we isolated the strong $h s p 83$ gene promoter from L. cuprina [30]. In D. melanogaster, the hsp 83 promoter has a high basal activity in all cells and is active in the germ-line [31]. The Lchsp 83 promoter was used to make more strongly expressed fluorescent protein marker genes and piggyBac transposase helper. These modifications led to an efficient and reliable method for germ-line transformation of L. cuprina [32]. Transgenic individuals are readily identified at the late embryo or larval stages and show strong whole body fluorescence (Figure 2).

\section{Genes that are sex-specifically expressed in L. cuprina}

In order to develop transgenic $L$. cuprina carrying the tetracycline-repressible female lethal system that was successful in $D$. melanogaster, we isolated a $L$. cuprina yolk protein gene promoter $(L c y p A)$ [33]. L. cuprina that carried an LcypA-lacZ transgene showed high levels of $\beta$-galactosidase in adult females, but only after a protein meal. Thus, although the LcypA promoter was female-specific, it was active at too late a stage for a FK system [33].

An alternative approach was to return to using introns from sex-specifically spliced transcripts to achieve female-specific gene expression at an earlier stage of development. Giuseppe Saccone and colleagues had shown that in the Mediterranean fruit fly, tra transcripts are sex-specifically spliced and splicing is autoregulated [34]. Moreover, RNAi-mediated knockdown of tra expression led to the transformation of XX individuals 

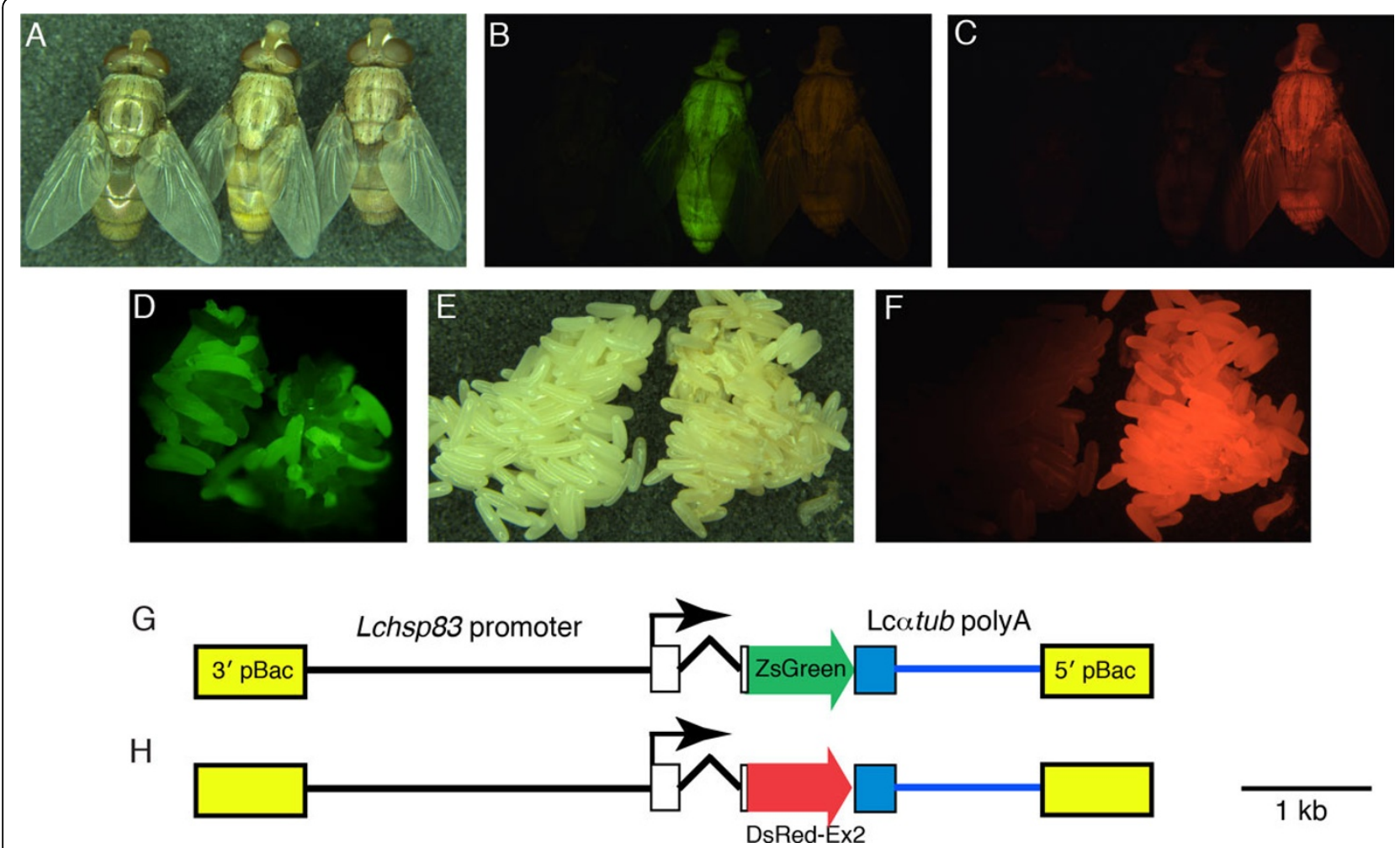

Figure 2 Marker gene expression in transgenic Lucilia cuprina. Adult flies or embryos were observed with either white light (A,E), a long pass GFP filter set (B,D) or a DsRed filter set (C,F). (A-C) Young adults (less than $2 \mathrm{~h}$ after eclosion) from the wild-type stock (left), a transgenic line that carries the ZsGreen marker (center) and a line that has the DsRed-Express 2 (DsRedex2) marker (right) are shown. (D) A mixture of nontransgenic and transgenic (ZsGreen marker) late stage embryos. The transgenic embryos show strong green fluorescence and are easily separated from the non-transgenic embryos. (E,F) Embryos from the wild-type stock (left) and from a transgenic line that carries the DsRedex2 marker (right). Transgenic individuals show bright green or red fluorescence in all cells from the mid-embryo to young adult stage. In older adults that have darker cuticles, fluorescence is much more difficult to detect (not shown). Consequently, we routinely screen for transgenic individuals at the embryo and larval stages. $(\mathrm{G}, \mathrm{H})$ Schematic representations of the pB[Lchsp83-ZsGreen] and pB[Lchsp83-DsRedex2] transformation vectors The vectors contains the $5^{\prime}$ flanking DNA, first exon and first intron from the Lchsp83 gene.

to males. This suggested that it could be possible to make a repressible female-male transformation system, which modeling suggests could be a very effective means for population control [35]. However, isolation of the L. cuprina tra gene proved to be a formidable challenge as the tra gene was poorly conserved between Drosophila and medfly. A fragment of the L. cuprina tra gene was isolated using PCR with degenerate primer pairs based on conserved amino acid motifs [36]. Subsequent analysis found that only the female tra transcript codes for TRA protein. The major male transcript includes an additional exon with several in-frame stop codons (Figure 3). As in C. capitata, the presence of multiple predicted TRA/TRA2 binding sites within the sex-specifically spliced first intron strongly suggested that splicing was autoregulated. The tra gene was shown to be essential for female development as injection of tra double-stranded RNA into the posterior end of embryos led to the development of XX adults with male genitalia. More recently we have isolated the tra gene from L. sericata, C. hominivorax and C. macellaria [37]. The overall organization of the tra genes from the four blow fly species is remarkably conserved, with a similar exon-intron arrangement and relative location of TRA/TRA2 binding sites (Figure 3). Lastly, we also isolated the L. cuprina $d s x$ gene and showed that $d s x$ transcripts are sex-specifically spliced as in Drosophila and housefly [38]. The presence of eight TRA/TRA2 sites in the female exon strongly suggested that $d s x$ splicing in female is regulated by TRA as in Drosophila.

\section{Development of transgenic "male-only" L. cuprina lines}

Moving to the U.S.A., the focus of the lab shifted to developing a transgenic male-only strain of the New World screwworm. However, since it was not possible to work with C. hominivorax in the U.S.A., we continued to work with L. cuprina (using a North American strain) as it is a close relative. Initially, we built a one-component system (Figure 4), based on the system developed by Luke Alphey and colleagues at Oxitec [39]. They found 


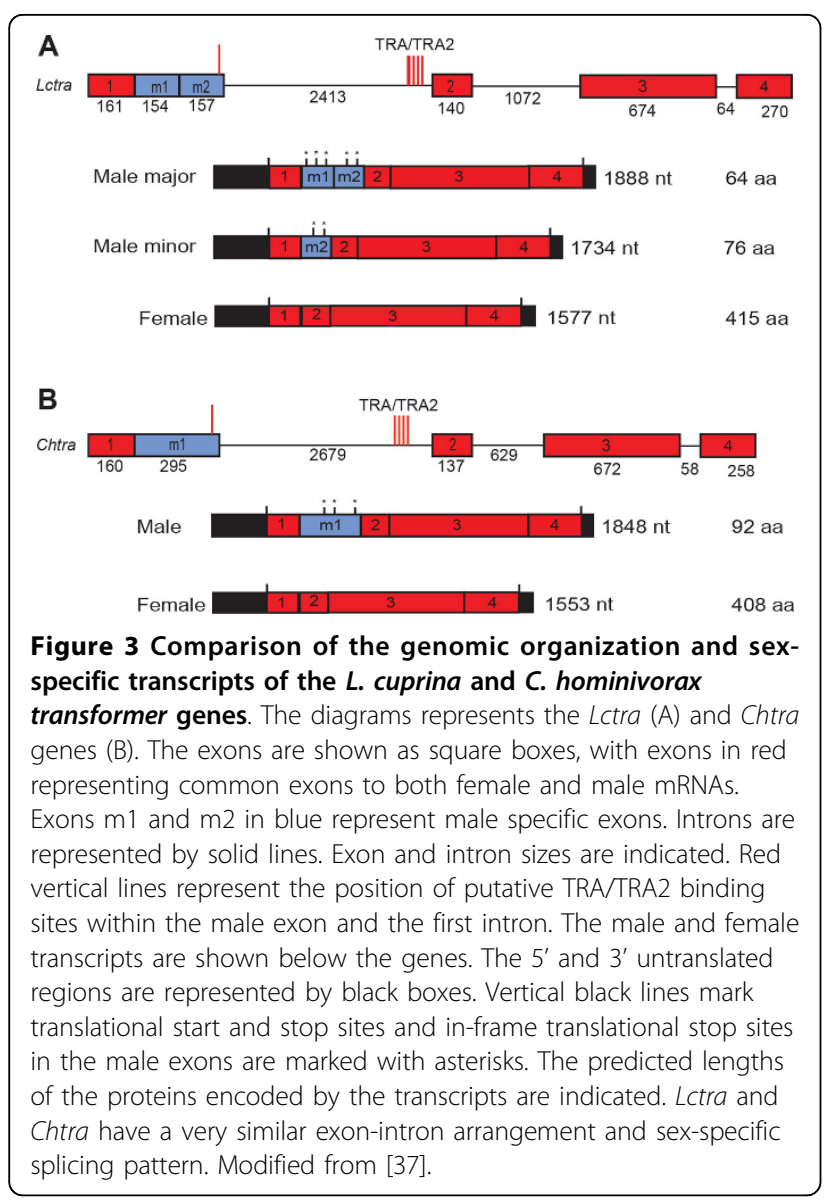

that overexpression of an auto-regulated tTA was lethal (usually pupal stage) but repressible by tetracycline. The lethality was thought to be due to a general interference with gene expression or "transcriptional squelching". The lethality can be made female-specific by incorporating the sex-specifically spliced tra intron into the tTA gene [39]. The appeal of making this system was that we had all of the necessary components, including the first intron from the C. hominivorax tra gene and an efficient transformation system. A disadvantage was that the late lethal period would not lead to any appreciable savings in the costs of diet for mass rearing. The initial system, FL3, used the core promoter from the D. melanogaster $h s p 70$ gene and multiple copies of the tTA binding site (tetO) upstream of the core promoter. Two transgenic $L$. cuprina FL3 lines were made. In one line, over 99\% of homozygous females died on diet that lacked tetracycline [40]. However, there was no decrease in female viability in heterozygous females. Further, homozygous females in the second line were fully viable on standard diet. Interestingly, in transgenic Drosophila FL3 lines, $100 \%$ of females died on diet lacking tetracycline. Thus the C. hominivorax tra intron was correctly sex-specifically spliced in D. melanogaster. However, it appeared that the system was not optimal for high levels of tTA expression in L. cuprina. We considered that expression could be improved by replacing the Drosophila core promoter with the core promoter from a L. cuprina hsp 70 gene [30]. Two gene constructs were made, FL11 and

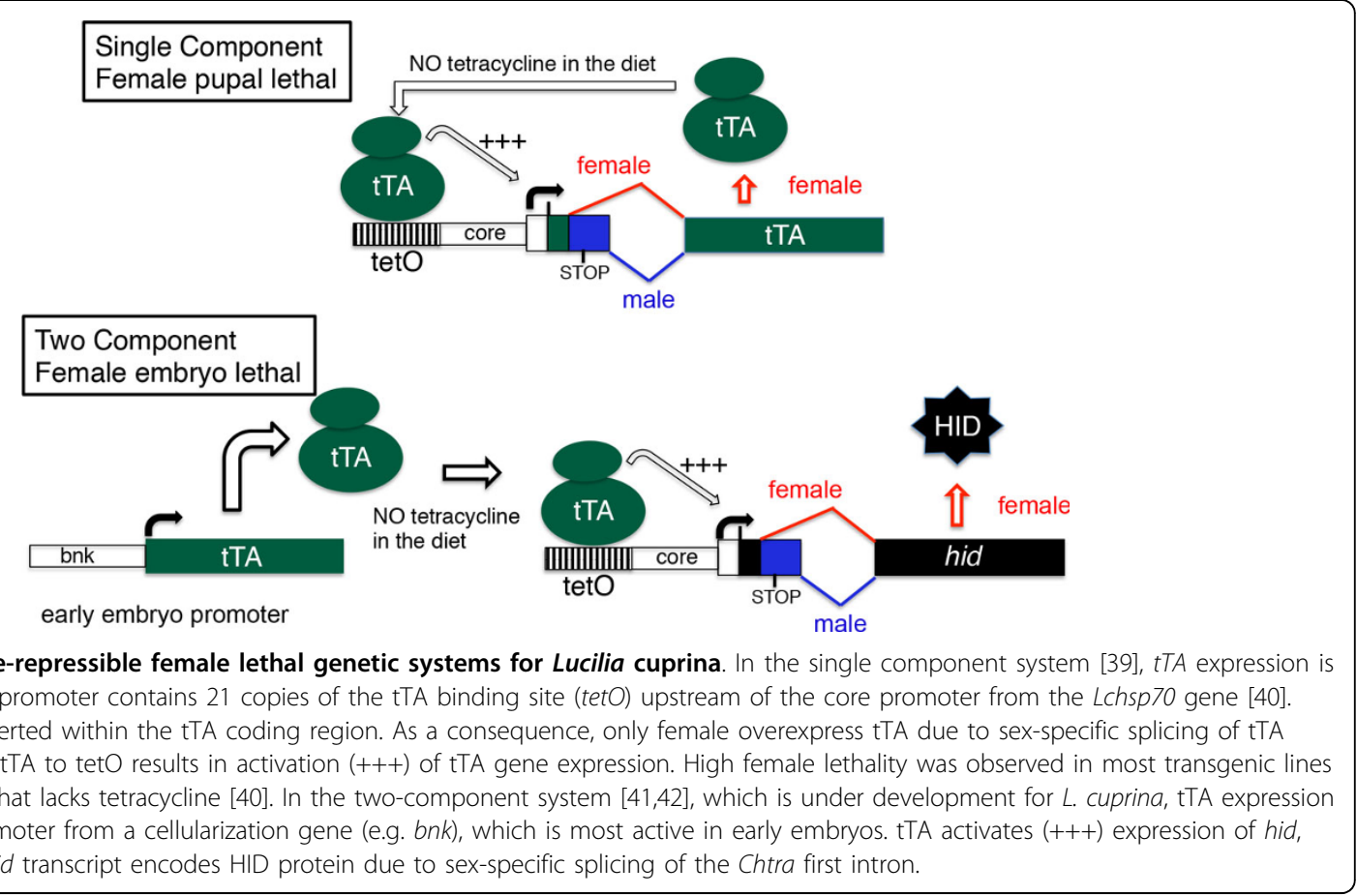


FL12, which differ slightly in the length of the core promoter. In three of five FL11 lines and two of three FL12 lines, $100 \%$ of homozygous females die on diet that lacks tetracycline [40]. Moreover, for three of the lines female lethality is dominant, with one copy of the transgene sufficient for $100 \%$ female lethality. Thus these lines could potentially be used for a RIDL genetic control program [40]. Surprisingly, the sexes could be reliably sorted by fluorescence or color at larval stages as females that overexpress tTA also overexpress the linked marker gene. It would appear that tTA bound to tetO is either directly enhancing expression of the Lshsp 83 promoter that drives the red fluorescent protein marker, or there is an indirect effect through changes to the structure of the local chromatin domain. Female larvae make so much of the marker protein that they show a crimson color under white light, easily distinguished from male larvae that have a very pale pink color.

To achieve female lethality at an earlier stage of development, we have also been working on a two-component genetic system (Figure 4). A similar system was used to develop A. suspensa and C. capitata transgenic embryonic sexing strains $[41,42]$. In this system a promoter from a cellularization gene (e.g. sry- $\alpha$ bnk, slam, nullo) that is most active in early embryos is used to drive expression of tTA. The effector is a tetO-hid construct that contains the sex-specifically spliced tra intron inserted in the hid gene. Thus in the absence of tetracycline, tTA is expressed in the early embryo and activates transcription of hid, but only female embryos die as only the female transcript codes for HID protein. To make transgenic embryonic sexing strains of L. cuprina, promoters from Lucilia cellularization genes and Lucilia cell death genes were required. Transcripts for the $L$. sericata bnk, rpr and hid genes were identified in RNA-seq libraries [43]. The L. sericata bnk promoter was isolated and shown to be active in transgenic L. cuprina embryos using a GFP reporter gene [44]. Expression of the L. sericata rpr and hid genes in transgenic Drosophila induced widespread apoptosis, with Lshid being particularly effective at inducing organismal death [44]. Thus with the required components on hand, we can proceed with assembling the gene constructs necessary to make transgenic sexing strains of L. cuprina where females die during embryogenesis.

\section{Conclusion}

Transgenic sexing strains of $L$. cuprina have been developed that carry a tetracycline -repressible female lethal genetic system. The successful development of these strains built upon prior research on female-lethal genetic systems in D. melanogaster, Lucilia germ-line transformation and sex determination genes in Lucilia. In the near future development of transgenic L. cuprina embryonic sexing strains should be possible as the required components have been isolated from Lucilia and shown to be functional. If the transgenic sexing strains were to be used for a genetic control program in Australia (or New Zealand), the next step would be to introgress the transgene into a more appropriate genetic background by crossing with a field strain from Australia. Cage studies would then be performed to evaluate the ability of the strains to suppress a population. The strains could be used for conventional SIT or a fertile release program. However, if fertile males are released, the male larval offspring will feed on tissue of live sheep, causing damage that may not be acceptable to growers. The systems that have been developed for L. cuprina should be directly portable to other blowfly livestock pests including the New World and Old World screwworm. We are actively working on making and evaluating transgenic sexing strains of New World screwworm (C. hominivorax).

\section{Competing interests}

The author declares that they have no competing interests.

\section{Authors' contributions}

Text and figures were prepared by the author.

\section{Acknowledgements}

We have been fortunate to receive funding from several sources over the past 15 years including from Wools of New Zealand, Australian Wool Innovation, Massey University, North Carolina State University, USDA-ARS and the NIFA Biotechnology Risk Assessment Grant Program. The project benefitted from discussions at International Atomic Energy Agency funded meetings for the Coordinated Research Project: "The Use of Molecular Tools to Improve the Effectiveness of SIT".

This article has been published as part of BMC Genetics Volume 15 Supplement 2, 2014: Development and evaluation of improved strains of insect pests for SIT. The full contents of the supplement are available online at http://www.biomedcentral.com/bmcgenet/supplements/15/S2. Publication of this supplement was funded by the International Atomic Energy Agency. The peer review process for articles published in this supplement was overseen by the Supplement Editors in accordance with BioMed Central's peer review guidelines for supplements. The Supplement Editors declare that they have no competing interests.

Published: 1 December 2014

\section{References}

1. Wardhaugh KG, Morton R, Bedo D, Horton BJ, Mahon RJ: Estimating the incidence of fly myiases in Australian sheep flocks: development of a weather-driven regression model. Med Vet Entomol 2007, 21(21):153-167.

2. Heath AC, Bishop DM: Flystrike in New Zealand: An overview based on a 16-year study, following the introduction and dispersal of the Australian sheep blowfly, Lucilia cuprina Wiedemann (Diptera: Calliphoridae). Vet Parasitol 2006, 137(3-4):333-344.

3. Sackett $D$, Holmes $P$, Abbott $K$, Jephcott $S$, Barber M: Assessing the economic cost of endemic disease on the profitability of Australian beef cattle and sheep producers. Meat and Livestock Australia Report AHW087 Sydney; 2006, 38-42.

4. Krafsur ES: Sterile insect technique for suppressing and eradicating insect population: 55 years and counting. J Agr Entomol 1998, 15(15):303-317.

5. Vargas-Teran M, Hofmann HC, Tweddle NE: Impact of screwworm eradication programmes using the sterile insect technique. In Sterile Insect Technique Principles and practice in area-wide integrated pest management. The Netherlands: Springer;Dyck VA, Hendrichs J, Robinson AS 2005:629-650. 
6. Foster GG, Vogt WG, Woodburn TL: Genetic analysis of field trials of sexlinked translocation strains for genetic control of the Australian sheep blowfly Lucilia cuprina (Wiedemann). Aust J Biol Sci 1985, 38:275-293.

7. Foster GG, Weller GL, James WJ, Paschalidis KM, McKenzie LJ: Advances in sheep blowfly genetic control in Australia. Management of insect pests: nuclear and related molecular and genetic techniques: 1993; Vienna 299-312, International Atomic Energy Agency.

8. Crystal MM: Sterilization of screwworm flies (Diptera: Calliphoridae) with gamma rays: restudy after two decades. J Med Entomol 1979, 15(15):103-108.

9. Foster GG, Vogt WG, Woodburn TL, Smith PH: Computer simulation of genetic control. Comparison of sterile males and field-female killing systems. Theor Appl Genet 1988, 76:870-879.

10. Black WCt, Alphey L, James AA: Why RIDL is not SIT. Trends Parasitol 2011, 27(8):362-370.

11. Rubin GM, Spradling AC: Genetic transformation of Drosophila with transposable element vectors. Science 1982, 218(218):348-353.

12. Belote JM: Sex determination in Drosophila melanogaster: from the $\mathrm{X}: \mathrm{A}$ ratio to doublesex. Semin Dev Biol 1992, 3:319-330.

13. Wilkins AS: Moving up the hierarchy: a hypothesis on the evolution of a genetic sex determination pathway. Bioessays 1995, 17(17):71-77.

14. Grether ME, Abrams JM, Agapite J, White K, Steller H: The head involution defective gene of Drosophila melanogaster functions in programmed cell death. Genes Dev 1995, 9(9):1694-1708.

15. Scott MJ, Heinrich JC, Li X: Progress towards the development of a transgenic strain of the Australian sheep blowfly (Lucilia cuprina) suitable for a male-only sterile release program. Insect Biochem Mol Biol 2004, 34(34):185-192.

16. Garabedian MJ, Shepherd BM, Wensink PC: A tissue-specific transcription enhancer from the Drosophila yolk protein 1 gene. Cell 1986, 45(45):859-867.

17. Gossen M, Bujard H: Tight control of gene expression in mammalian cells by tetracycline-responsive promoters. P Natl Acad Sci USA 1992, 89(89):5547-5551.

18. Heinrich JC, Scott MJ: A repressible female-specific lethal genetic system for making transgenic insect strains suitable for a sterile-release program. P Natl Acad Sci USA 2000, 97(97):8229-8232.

19. Thomas DD, Donnelly CA, Wood RJ, Alphey LS: Insect population control using a dominant, repressible, lethal genetic system. Science 2000, 287(287):2474-2476.

20. Schliekelman P, Gould F: Pest control by the release of insects carrying a female-killing allele on multiple loci. J Econ Entomol 2000, 93(93):1566-1579.

21. Harvey-Samuel T, Ant T, Gong H, Morrison NI, Alphey L: Population-level effects of fitness costs associated with repressible female-lethal transgene insertions in two pest insects. Evol Appl 2014, 7(7):597-606.

22. Leftwich PT, Koukidou M, Rempoulakis P, Gong HF, Zacharopoulou A, Fu G, Chapman T, Economopoulos A, Vontas J, Alphey L: Genetic elimination of field-cage populations of Mediterranean fruit flies. Proc Biol Sci 2014, 281(1792).

23. Handler AM, Gomez SP, O'Brochta DA: A functional analysis of the $P$-element gene-transfer vector in insects. Arch Insect Biochem Physiol 1993, 22(3-4):373-384.

24. Coates CJ, Turney CL, Frommer M, O'Brochta DA, Atkinson PW: Interplasmid transposition of the mariner transposable element in nondrosophilid insects. Mol Gen Genet 1997, 253(6):728-733.

25. Heinrich JC, Li X, Henry RA, Haack N, Stringfellow L, Heath AC, Scott MJ: Germ-line transformation of the Australian sheep blowfly Lucilia cuprina. Insect Mol Biol 2002, 11(1):1-10.

26. Horn C, Schmid BG, Pogoda FS, Wimmer EA: Fluorescent transformation markers for insect transgenesis. Insect Biochem Mol Biol 2002, 32(10):1221-1235.

27. Handler AM, Harrell RA: Germline transformation of Drosophila melanogaster with the piggyBac transposon vector. Insect Mol Biol , 2 1999, 8(8):449-457.

28. Handler AM, Harrell RA: Transformation of the Caribbean fruit fly, Anastrepha suspensa, with a piggyBac vector marked with polyubiquitinregulated GFP. Insect Biochem Mol Biol , 2 2001, 31(31):199-205.

29. Allen ML, Handler AM, Berkebile DR, Skoda SR: piggyBac transformation of the New World screwworm, Cochliomyia hominivorax, produces multiple distinct mutant strains. Med Vet Entomol 2004, 18(18):1-9.
30. Concha C, Edman RM, Belikoff EJ, Schiemann AH, Carey B, Scott MJ: Organization and expression of the Australian sheep blowfly (Lucilia cuprina) $h s p 23, h s p 24, h s p 70$ and $h s p 83$ genes. Insect Mol Biol 2012, 21(21):169-180.

31. Xiao H, Lis JT: Heat shock and developmental regulation of the Drosophila melanogaster hsp83 gene. Mol Cell Biol 1989, 9(9):1746-1753.

32. Concha C, Belikoff EJ, Carey BL, Li F, Schiemann AH, Scott MJ: Efficient germ-line transformation of the economically important pest species Lucilia cuprina and Lucilia sericata (Diptera, Calliphoridae). Insect Biochem Mol Biol 2011, 41(41):70-75.

33. Scott MJ, Atapattu A, Schiemann AH, Concha C, Henry R, Carey BL, Belikoff EJ, Heinrich JC, Sarkar A: Organisation and expression of a cluster of yolk protein genes in the Australian sheep blowfly, Lucilia cuprina. Genetica 2011, 139(1):63-70.

34. Pane A, Salvemini M, Delli Bovi P, Polito C, Saccone G: The transformer gene in Ceratitis capitata provides a genetic basis for selecting and remembering the sexual fate. Development 2002, 129(129):3715-3725.

35. Schliekelman P, Ellner S, Gould F: Pest control by genetic manipulation of sex ratio. J Econ Entomol 2005, 98(1):18-34.

36. Concha C, Scott MJ: Sexual development in Lucilia cuprina (Diptera, Calliphoridae) is controlled by the transformer gene. Genetics 2009, 182(182):785-798.

37. Li F, Vensko SP, Belikoff EJ, Scott MJ: Conservation and Sex-Specific Splicing of the transformer Gene in the Calliphorids Cochliomyia hominivorax, Cochliomyia macellaria and Lucilia sericata. PLoS One 2013, 8(8):e56303.

38. Concha C, Li F, Scott MJ: Conservation and sex-specific splicing of the doublesex gene in the economically important pest species Lucilia cuprina. J Genet 2010, 89(89):279-285.

39. Fu G, Condon KC, Epton MJ, Gong P, Jin L, Condon GC, Morrison NI, Dafa'alla TH, Alphey L: Female-specific insect lethality engineered using alternative splicing. Nat Biotechnol 2007, 25(3):353-357.

40. Li F, Wantuch HA, Linger RJ, Belikoff EJ, Scott MJ: Transgenic sexing system for genetic control of the Australian sheep blow fly Lucilia cuprina. Insect Biochem Mol Biol 2014, 51:80-88.

41. Schetelig MF, Handler AM: A transgenic embryonic sexing system for Anastrepha suspensa (Diptera: Tephritidae). Insect Biochem Mol Biol 2012, 42(42):790-795.

42. Ogaugwu CE, Schetelig MF, Wimmer EA: Transgenic sexing system for Ceratitis capitata (Diptera: Tephritidae) based on female-specific embryonic lethality. Insect Biochem Mol Biol 2013, 43(43):1-8.

43. Sze SH, Dunham JP, Carey B, Chang PL, Li F, Edman RM, Fjeldsted C, Scott MJ, Nuzhdin SV, Tarone AM: A de novo transcriptome assembly of Lucilia sericata (Diptera: Calliphoridae) with predicted alternative splices, single nucleotide polymorphisms and transcript expression estimates. Insect Mol Biol 2012, 21(21):205-221.

44. Edman RM, Linger RJ, Belikoff EJ, Li F, Sze SH, Tarone AM, Scott MJ: Functional characterization of calliphorid cell death genes and cellularization gene promoters for controlling gene expression and cell viability in early embryos. Insect Mol Biol 2014, in press.

doi:10.1186/1471-2156-15-S2-S3

Cite this article as: Scott: Development and evaluation of male-only strains of the Australian sheep blowfly, Lucilia cuprina. BMC Genetics 2014 15(Suppl 2):S3.

\section{Submit your next manuscript to BioMed Central and take full advantage of:}

- Convenient online submission

- Thorough peer review

- No space constraints or color figure charges

- Immediate publication on acceptance

- Inclusion in PubMed, CAS, Scopus and Google Scholar

- Research which is freely available for redistribution 